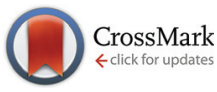

Cite this: Dalton Trans., 2015, 44, 12365

Received 18th January 2015

Accepted 17th March 2015

DOI: $10.1039 / c 5 d t 00236 b$

www.rsc.org/dalton

\section{Magnesium amino-bis(phenolato) complexes for the ring-opening polymerization of rac-lactide $\uparrow$}

\author{
Katalin Devaine-Pressing, ${ }^{a}$ Joshua H. Lehr, ${ }^{a}$ Michelle E. Pratt, ${ }^{a}$ Louise N. Dawe, $t^{a}, b$ \\ Amy A. Sarjeant ${ }^{\mathrm{C}}$ and Christopher M. Kozak ${ }^{{ }^{a}}$
}

\section{Introduction}

Polylactide continues to be at the forefront of biodegradable, biosourced and biocompatible polymer synthesis. It is central to the development of sustainable polymers, an area of critical importance for the design of new materials that reduce environmental and health impacts resulting from their manufacture, use, and their end-of-life properties. ${ }^{1-4}$ The array of different metal complexes studied for the ring-opening polymerization (ROP) of lactide has been described in several reviews $^{5-8}$ and examples of metal-containing initiators vary considerably in terms of the metal centre and ligands employed. Complexes of amino-bis(phenolates) exhibit interesting structural and electronic properties, as well as catalytic behaviour; the variety of metal complexes with this ligand class has also been reviewed. ${ }^{9}$ Derivatives of this ligand class have been used in main group and d-block metal chemistry, including lithium, ${ }^{10-18}$ magnesium, ${ }^{19-25}$ calcium, ${ }^{26}$ rareearths, ${ }^{27,28}$ zinc $^{20,29-37}$ aluminum, ${ }^{7,38,39}$ zirconium $^{40,41}$ and titanium. ${ }^{42}$ Many of these complexes have been reported to be excellent initiators for the ROP of cyclic esters such as lactide and $\varepsilon$-caprolactone. For the ROP of cyclic esters, earth

\footnotetext{
${ }^{a}$ Department of Chemistry, Memorial University of Newfoundland, St. John's, Newfoundland, Canada A1B 3X7. E-mail: ckozak@mun.ca; Tel: +1-709-864-8082 ${ }^{b}$ C-CART X-ray Diffraction Laboratory, Memorial University of Newfoundland, St. John's, Newfoundland, Canada

${ }^{c}$ Department of Chemistry, Northwestern University, 2145 Sheridan Rd, Evanston, IL 60208, USA

$\dagger$ Electronic supplementary information (ESI) available: Crystallographic experimental and spectroscopic data (PDF). CCDC 1043113. For ESI and crystallographic data in CIF or other electronic format see DOI: 10.1039/c5dt00236b ¥Current Address: Department of Chemistry and Biochemistry, Wilfrid Laurier University, Waterloo, Ontario, Canada
}

abundant alkali and alkaline earth metal compounds have become particularly important in the search for efficient, stable, inexpensive and non-toxic catalysts. We have previously reported the structures and catalytic lactide ROP activity of lithium and potassium amino-bis(phenolato) compounds. ${ }^{43,44}$ Magnesium compounds also have great potential as ROP catalysts for the preparation of PLA particularly for biomedical applications, as $\mathrm{Mg}$ is a biocompatible and non-toxic metal and thus the residue of these metals in the resulting polylactide is not of great concern. ${ }^{45,46}$ Furthermore, magnesium compounds have been shown to elicit high reaction rates for copolymerization of $\mathrm{CO}_{2}$ and epoxides. ${ }^{47}$

Magnesium complexes reported by $\mathrm{Ma}$ and co-workers exhibited some of the highest activities in ROP of cyclic esters by this metal. ${ }^{48,49}$ The high activity for the ROP of rac-lactide may be due to the monomeric nature of these magnesium bis(silyl)amido complexes supported by tetradentate monophenolate ligands and the presence of a reactive monodentate amido ligand. A TOF of $36560 \mathrm{~h}^{-1}$ was achieved when 10000 equiv. of rac-lactide was converted to polylactide in 15 minutes at $25{ }^{\circ} \mathrm{C}$ in the absence of any co-catalyst. One of these complexes showed very high activity even under melt conditions at $110{ }^{\circ} \mathrm{C}$ giving $72 \%$ conversion with a TOF of $86880 \mathrm{~h}^{-1}$. Magnesium compounds supported by tridentate monophenolate Schiffbase ligands and benzyl alkoxide also proved active for L-lactide polymerization in $\mathrm{CH}_{2} \mathrm{Cl}_{2}$ solutions. ${ }^{21}$ In both these cases, it is likely the monodentate amido or alkoxide ligand that serves as the initiation site.

In light of these high activities, we investigated the activity of magnesium amino-bis(phenolato) complexes towards ROP of rac-lactide under melt conditions and in solution. Magnesium complexes of aminophenolate ligands have previously been reported by others but their activity for ROP of lactides 
was not tested or they showed very low or no activity. ${ }^{50-53}$ In this report, we present the synthesis and characterization of two new magnesium amine-bis(phenolate) complexes that show good lactide ROP activity in both melt and solution conditions.

\section{Results and discussion}

\section{Synthesis and characterization of proligands and magnesium complexes}

Tetradentate tripodal amine-bis(phenol) proligands (Scheme 1) were synthesized via a modified Mannich condensation reaction in water. ${ }^{54}$ The substituted phenols contained $t$-butyl groups in the ortho positions and methoxy $\left(\mathrm{H}_{2}[\mathbf{L 1}]\right)$ or

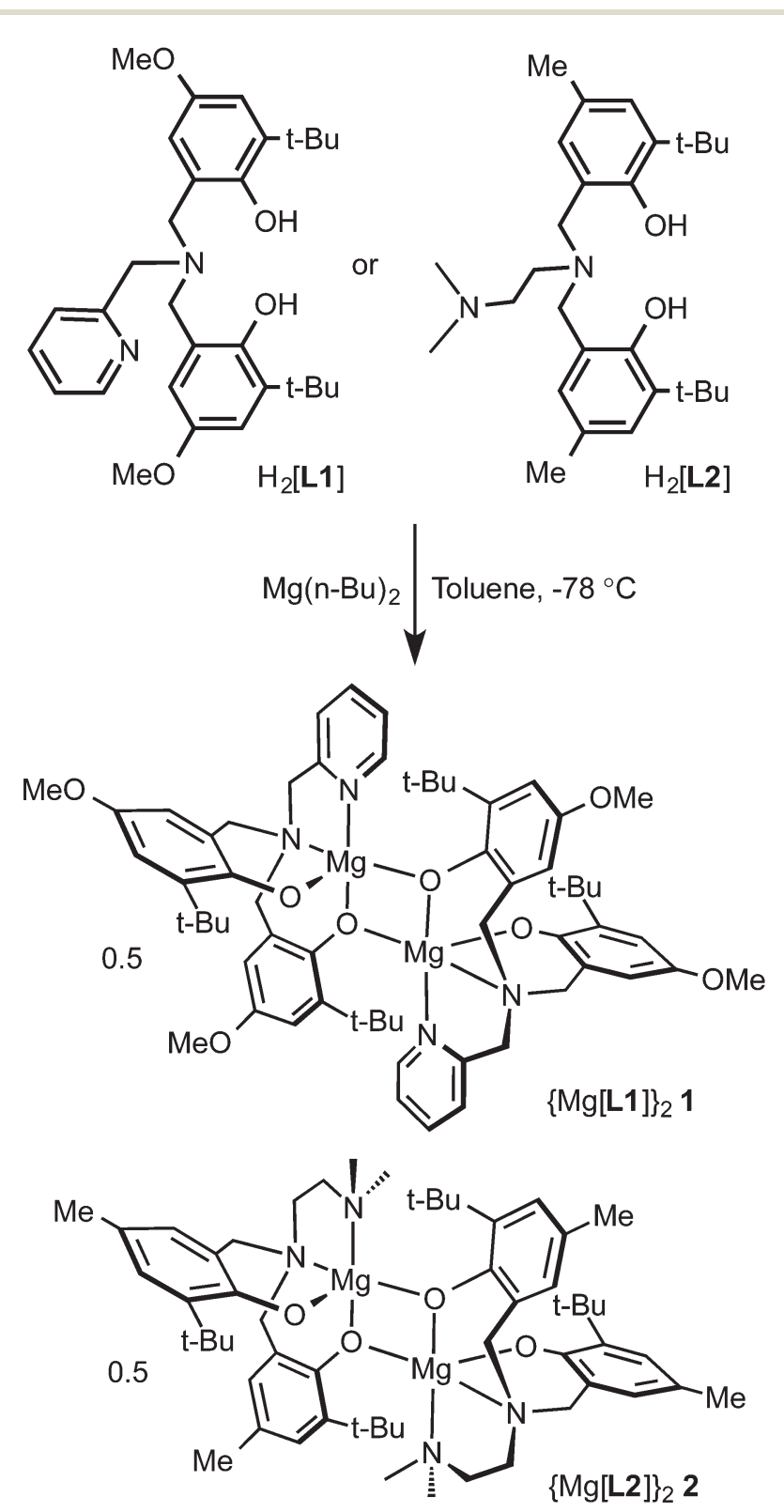

Scheme 1 Synthesis of complexes 1 and 2. methyl groups $\left(\mathrm{H}_{2}[\mathbf{L} 2]\right)$ para to the hydroxyl group. The proligands possessed pyridyl $\left(\mathrm{H}_{2}[\mathbf{L} 1]\right)$ or dimethylaminoethyl $\left(\mathrm{H}_{2}[\mathbf{L 2}]\right)$ groups as the neutral pendant $\mathrm{N}$-donors. The synthesis of $\mathrm{H}_{2}[\mathbf{L 1}]$ using a four step procedure ${ }^{55}$ and without the addition of any further solvents ${ }^{56}$ was previously reported. The synthesis of $\mathrm{H}_{2}[\mathbf{L} 2]$ in methanol was reported by Bochmann and co-workers. ${ }^{53}$

The corresponding ligand was reacted with one equivalent of $\operatorname{di}\left(n\right.$-butyl)magnesium in toluene at $-78{ }^{\circ} \mathrm{C}$ to afford complexes 1 and 2 (Scheme 1). The NMR spectra of complexes 1 and 2 in non-coordinating solvents revealed that the compounds exist as dimers in solution. The ${ }^{1} \mathrm{H}-\mathrm{NMR}$ spectrum of 2 in $\mathrm{C}_{6} \mathrm{D}_{6}$ showed two $t$-butyl environments implying inequivalent phenolates. This was further supported by the existence of four aromatic proton resonances arising from the phenolate rings occupying inequivalent coordination sites at the magnesium centres. The methylene resonances exist as four doublets. Two doublets are expected for a monometallic complex given the diastereotopic environments resulting from coordination to the metal centre. The existence of the four doublets arises from asymmetric phenolate sites where one phenolate of each ligand occupies a bridging position between two magnesium ions. The solid-state structure of compound 2 confirmed the proposed connectivity (see below). In coordinating solvents, such as pyridine or DMSO, the NMR spectra are consistent with monometallic compounds. The ${ }^{1} \mathrm{H}$ NMR spectra of 1 in $\mathrm{C}_{6} \mathrm{D}_{6}$ or toluene- $\mathrm{d}_{8}$ showed the presence of several isomers suggesting the existence of dimeric species but also of more than one structural isomer (e.g. syn and anti oriented pendent donors) present in solution. Similar isomerism has been observed in zirconium amine-tris(phenolates). ${ }^{57}$

MALDI-TOF mass spectrometry (see Fig. S1 and S2 in ESI $\dagger$ ) showed complexes $\mathbf{1}$ and $\mathbf{2}$ exhibit dimeric structures in the gas phase as well as in solution and the solid state. Peaks at $\mathrm{m} / \mathrm{z} 1028.50$ (rel. intensity 100\%) and $\mathrm{m} / \mathrm{z} 514.26$ (58\%) corresponding to the dimer and monomer fragment ions, respectively, were observed for complex 1 . For complex 2, the peak assigned to the dimer at $m / z 924.52$ was very weak (3\%) and the peak at $\mathrm{m} / z 462.25(100 \%)$ corresponds to the monomer.

Colourless crystals of 2 suitable for single crystal X-ray diffraction were obtained from saturated toluene solutions at $-35{ }^{\circ} \mathrm{C}$. The solid-state molecular structure with selected bond lengths and angles is shown in Fig. 1. Crystallographic and structure refinement data can be found in Table S1 in ESI. $\dagger$ The dimeric structure with chemically distinct phenolate groups is consistent with the NMR studies discussed above. Each magnesium centre is five-coordinate and bound to two nitrogen donors and three oxygen donors. Four of the coordination sites are occupied by the chelating diamine-bis(phenolate) ligand, while the fifth coordination site is occupied by a bridging phenolate oxygen. The non-planar $\mathrm{Mg}_{2} \mathrm{O}_{2}$ core exhibits a $\mathrm{O}(2)-\mathrm{Mg}(1)-\mathrm{O}(2)^{*}-\mathrm{Mg}(1)^{*}$ torsion angle of $32.69(4)^{\circ}$. The magnesium complexes that show polymerization activity are believed to initiate cyclic ester ring-opening polymerizations through a coordination insertion mechanism; ${ }^{6,45}$ therefore, the creation of a vacant site by breaking the $\mathrm{Mg}_{2} \mathrm{O}_{2}$ ring (in the 


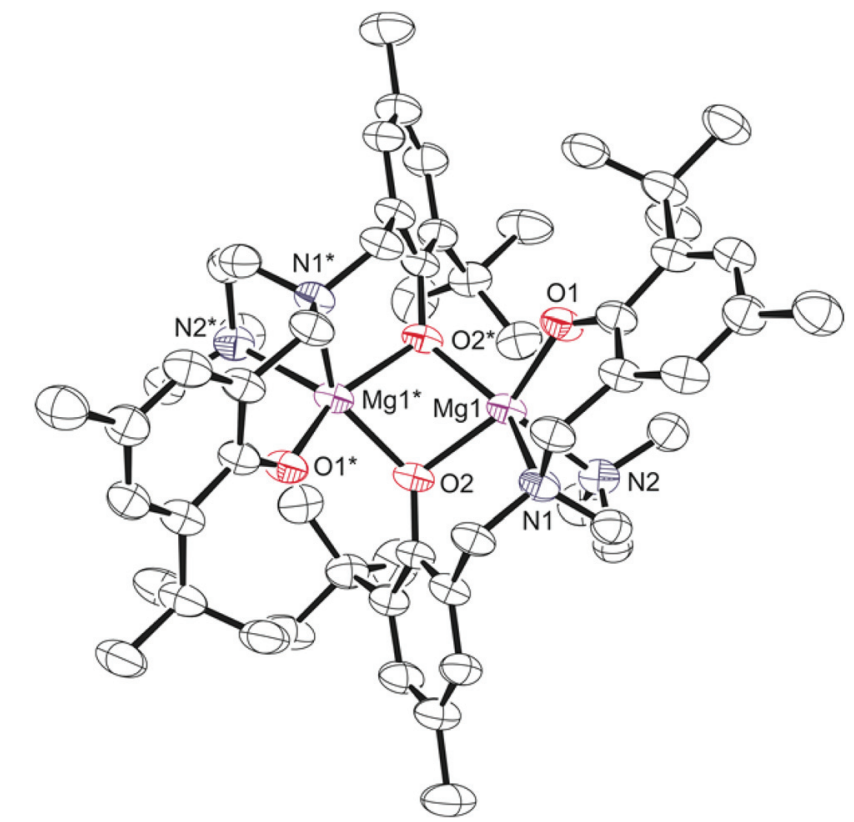

Fig. 1 Partially labelled molecular structure (ORTEP) of the dimer of complex 2 . Thermal ellipsoids are drawn at $50 \%$ probability and $\mathrm{H}$ atoms are excluded for clarity. Selected bond lengths (Å): $M g(1)-O(1), 1.950(2)$; $\mathrm{Mg}(1)-\mathrm{O}(2), \quad 2.049(2) ; \mathrm{Mg}(1)-\mathrm{O}(2)^{*}, \quad 2.049(2) ; \mathrm{Mg}(1)-\mathrm{N}(1), 2.243(3)$; $\mathrm{Mg}(1)-\mathrm{N}(2), 2.265(3)$. Bond angles $\left({ }^{\circ}\right)$ : $\mathrm{O}(1)-\mathrm{Mg}(1)-\mathrm{O}(2), 153.48(10)$; $\mathrm{O}(1)-\mathrm{Mg}(1)-\mathrm{N}(1), 88.25(9) ; \mathrm{O}(2)-\mathrm{Mg}(1)-\mathrm{O}(2)^{*}, 74.53(9) ; \mathrm{Mg}(1)-\mathrm{O}(2)-$ $\mathrm{Mg}(1)^{*}, \quad 95.71(8), \quad \mathrm{O}(2)^{*}-\mathrm{Mg}(1)-\mathrm{N}(1), \quad 140.38(9) ; \quad \mathrm{O}(2)-\mathrm{Mg}(1)-\mathrm{N}(2)$, 102.07(9); O(1)-Mg(1)-O(2)*, 91.64(9). *Symmetry operations used to generate equivalent atoms: $1-x, y, \frac{1}{2}-z$.

presence of a polar monomer or a coordinating solvent, for example) may induce activity in these typically inactive bimetallic complexes. NMR studies of monomer formation in the presence of benzyl alcohol (a lactide ROP cocatalyst) are discussed below. The $\mathrm{Mg}(1)-\mathrm{O}(1)$ bond (1.950(2) $\AA$ ) in 2 is considerably shorter than the $\mathrm{Mg}(1)-\mathrm{O}(2)$ bond $(2.049(2) \AA)$, because of the bridging bonding mode of the $\mathrm{O}(2)$ atom. The bond lengths for $\mathrm{Mg}(1)-\mathrm{N}(1)$ and $\mathrm{Mg}(1)-\mathrm{N}(2)$ were very similar at 2.243(3) $\AA$ and 2.265(3) $\AA$, respectively, and are within the range observed in similar complexes. ${ }^{50-52}$

A brief comparison of the structural properties of magnesium amine-bis(phenolate) complexes follows. The trigonality index, ${ }^{58} \tau$, for 2 is 0.27 at both magnesium centres, which more closely approaches a distorted square pyramidal $(\tau=0)$ rather than a trigonal bipyramidal geometry $(\tau=1)$. The related magnesium complex reported by Jerzykiewicz and coworkers differs from 2 in that it contains one methyl substituent at the para position of the phenolate ring and no substituents at the ortho position resulting in a much less sterically encumbered metal site. ${ }^{50}$ This is manifested in a rhombic $\mathrm{Mg}_{2} \mathrm{O}_{2}$ core that is nearly perfectly planar, possessing a sum of angles of $359.9^{\circ}$. The $\tau$ values for this compound are 0.35 and 0.61 for $\mathrm{Mg}(1)$ and $\mathrm{Mg}(2)$, respectively, indicating geometries around the metal centres that are intermediate to square pyramidal and trigonal bipyramidal.
A similar complex was reported by Sobota and co-workers possessing the tripodal amine-bis(phenolate) ligand, $\mathrm{N}, \mathrm{N}$-bis(3,5-di-tert-butylbenzyl-2-hydroxy)tetrahydrofurfurylamine. ${ }^{52} \mathrm{~A}$ dimeric complex was observed in $\mathrm{C}_{6} \mathrm{D}_{6}$ solutions and in the solid state, where it displayed a distorted rhombic $\mathrm{Mg}_{2} \mathrm{O}_{2}$ core whose sum of angles was $346.8^{\circ}$. The structure exhibited $\tau$ values for the two pentacoordinate magnesium centres that were almost identical at 0.41 and 0.39 , intermediate to trigonal bipyramidal and square pyramidal arrangements, similar to complex 2. This complex, however, also proved to be inactive in ROP of L-lactide at $25^{\circ} \mathrm{C}$ in toluene.

A related phenolate-bridged magnesium dimer possessing $N, N^{\prime}$-bis(2-hydroxido-3,5-di-tert-butyl)- $N, N^{\prime}$-dimethylethane-1,2diamine (salan) ligands was reported by Davidson, O'Hara and co-workers. ${ }^{51}$ As in the compound reported by Jerzykiewicz, each magnesium ion in this structure possesses different coordination environments with $\mathrm{Mg}(1)$ and $\mathrm{Mg}(2)$ centres having $\tau$ values of 0.32 and 0.25 , respectively. $\mathrm{A} \mathrm{Mg}_{2} \mathrm{O}_{2}$ core is also present in this structure with a sum of angles of $357.6^{\circ}$. ${ }^{13} \mathrm{C}$ - and ${ }^{1} \mathrm{H}$-NMR spectra for this compound in aromatic solvents suggested a dimeric structure in solution, similar to complex 2. Two distinct phenolate environments and complicated methylene resonances indicate the dimer remains intact in non-coordinating aromatic solvents. This complex showed no activity in ring opening polymerization of lactide even at $110{ }^{\circ} \mathrm{C}$ in solution, which was attributed to the bulkiness of the ligand and the persistence of the dimeric nature of the complex in non-coordinating, aromatic solvents.

Magnesium $\quad N, N$-bis(3,5,-di-tert-butylbenzyl-2-hydroxy)dimethylethylenediamine was prepared by Bochmann and coworkers using magnesium bis[bis(trimethylsilyl)amide] (instead of the more commonly used di(n-butyl)magnesium) to give a complex that, although not structurally authenticated, is expected to be similar to those discussed above. ${ }^{53}$ This complex showed poor activity (only $5 \%$ conversion) in the ROP of $\varepsilon$-caprolactone (CL) in toluene at $60{ }^{\circ} \mathrm{C}$ for a [CL]: [Mg] ratio of $200: 1$.

Although the solution-state ROP experiments of the previously reported magnesium-bis(phenolate) complexes were not encouraging, we believed that under melt conditions compounds 1 and 2 may exhibit activity. Indeed, rac-lactide can be polymerized by $\mathbf{1}$ and 2 in the bulk at temperatures above $125{ }^{\circ} \mathrm{C}$ and, to our surprise, in toluene solutions at $90{ }^{\circ} \mathrm{C}$.

\section{Ring opening polymerization in the melt}

Melt phase ROP has attracted much interest recently as it offers a viable technique for industry. ${ }^{59}$ There are examples for lactide ROP in the melt catalysed by a variety of metal complexes, such as sulphonamide-supported aluminum complexes, ${ }^{60} \mathrm{Ni}$ (II) and $\mathrm{Ni}(\mathrm{II})-\mathrm{Sm}(\mathrm{III})$ salen complexes, ${ }^{61}$ aluminumsalen $^{62}$ and salen-like ${ }^{63}$ complexes, zirconium and hafnium amine tris(phenolate) alkoxides, ${ }^{64}$ but solvent-free lactide ROP with an earth-abundant, non-toxic metal initiator at low catalyst loading still remains a challenge. Magnesium complexes $\mathbf{1}$ and 2 were assessed for their capabilities toward the ROP of rac-lactide under industrially relevant melt (solvent-free) conditions above $125^{\circ} \mathrm{C}$. The polymerization results are summar- 
Table 1 Solvent-free (melt) rac-lactide polymerization by complexes 1 and 2

\begin{tabular}{|c|c|c|c|c|c|c|c|c|c|}
\hline Entry $^{a}$ & Complex & Time (min) & $T\left({ }^{\circ} \mathrm{C}\right)$ & {$[\mathrm{Mg}]:[r a c-\mathrm{LA}]:[\mathrm{BnOH}]$} & Conv. $^{b}(\%)$ & Activity $^{c}\left(\mathrm{~kg} \mathrm{~mol}^{-1} \mathrm{~h}^{-1}\right)$ & $M_{\mathrm{n}}^{d}\left(\right.$ calc'd $\left.^{\prime}\right)$ & $M_{\mathrm{n}}^{e}(\mathrm{GPC})$ & $D\left(M_{\mathrm{w}} / M_{\mathrm{n}}\right)$ \\
\hline 1 & 1 & 100 & 125 & $1: 100: 0$ & 99 & 8.56 & 14400 & 20300 & 2.74 \\
\hline 2 & 1 & 100 & 125 & $1: 100: 1$ & 99 & 8.56 & 14400 & 11300 & 1.77 \\
\hline 4 & 1 & 100 & 125 & $1: 500: 1$ & 98 & 42.4 & 70600 & 9700 & 2.01 \\
\hline 5 & 2 & 100 & 125 & $1: 100: 0$ & 100 & 8.65 & 14400 & 16500 & 2.40 \\
\hline 6 & 2 & 100 & 125 & $1: 100: 1$ & 82 & 6.23 & 14400 & 7200 & 1.54 \\
\hline 7 & 2 & 100 & 125 & $1: 500: 0$ & 72 & 31.1 & 51800 & 30600 & 2.72 \\
\hline 10 & 1 & 100 & 125 & $1: 1000: 1$ & 93 & 80.4 & 133900 & 42900 & 1.24 \\
\hline 11 & 1 & 180 & 125 & $1: 1000: 0$ & 93 & 44.7 & 133900 & 74300 & 1.05 \\
\hline 12 & 1 & 180 & 125 & $1: 1000: 1$ & 89 & 42.8 & 128200 & 50100 & 1.24 \\
\hline 13 & 1 & 100 & 150 & $1: 1000: 0$ & 92 & 79.6 & 132500 & 35200 & 1.22 \\
\hline 14 & 1 & 100 & 150 & $1: 1000: 1$ & 96 & 83.0 & 138200 & 70290 & 1.08 \\
\hline 15 & 1 & 180 & 150 & $1: 2500: 0$ & 16 & 19.2 & 57600 & $\mathrm{ND}^{f}$ & ND \\
\hline
\end{tabular}

${ }^{a}$ All polymerization reactions were carried out in neat $r a c$-lactide $(0.5-0.6 \mathrm{~g}) \cdot{ }^{b}$ Conversion determined by ${ }^{1} \mathrm{H}$-NMR. ${ }^{c}$ Calculated as mass of lactide

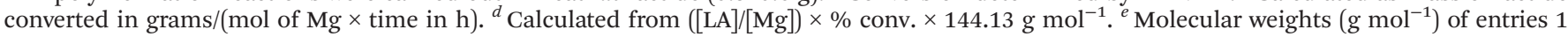
to 8 determined by gel permeation chromatography (GPC) in $\mathrm{CHCl}_{3}$ calibrated against polystyrene standards using the Mark-Houwink correction of $0.58 .{ }^{65} \mathrm{GPC}$ of entries 9 to 15 were conducted in THF by triple detection. See Experimental for full details. ${ }^{f}$ ND $=$ Not Determined, yield too low.

ized in Table 1. Polymerization occurred with or without a coinitiator (benzyl alcohol, BnOH). In general, the polymer molecular weights observed by gel permeation chromatography were lower than expected, likely due to mass transfer issues in the melt. Also, lower molecular weight polymers were obtained when $\mathrm{BnOH}$ was used, but the dispersity values were lower indicating a more controlled polymerization. Higher molecular weight and monodisperse polymers were obtained when catalyst loading is decreased. Interestingly, the physical appearance of the polymers was found to depend on whether $\mathrm{BnOH}$ was used (which gave thin films) or not (which gave crystalline white solids). The mechanical properties of the polymers are discussed below. Complex 1 showed slightly better conversions than complex $\mathbf{2}$, so $\mathbf{1}$ was chosen to carry out further reactions.

When the catalyst loading was lowered to $0.1 \mathrm{~mol} \%$ (entries 9-14), lactide conversion remained high translating to an increase in activity with good control as shown by the narrow dispersities of the polymers obtained. Polymerization remained controlled even in the absence of $\mathrm{BnOH}$ co-initiator. Highest molecular weights were obtained when the polymerization was run for $180 \mathrm{~min}$ (entry 11) or when the temperature was raised to $150{ }^{\circ} \mathrm{C}$ (entry 14). Activity was still observed upon further decreasing the catalyst loading to $0.04 \mathrm{~mol} \%$ at this temperature, but with low conversion (16\%) (entry 15).

Kinetic studies performed with $\mathbf{1}$ under conditions given in Table 1, entry 3 revealed that the polymerization reached completion in 60 minutes (see Table 2). Molecular weights increase with increasing time and conversion and the dispersity values are generally low (1.14-1.40). The difference in conversion between entry 5 and 6 is not significant, but the difference in molecular weight is in accordance with the phenomenon observed earlier in Table 1, entry 11 that it is favourable to leave the polymerization to occur for longer time to achieve higher molecular weight polymers.
Table 2 Time dependence of melt-phase rac-lactide polymerization by 1

\begin{tabular}{llllrl}
\hline Entry $^{a}$ & $\begin{array}{l}\text { Time } \\
(\mathrm{min})\end{array}$ & $\begin{array}{l}\text { Conv. }^{b} \\
(\%)\end{array}$ & $\begin{array}{l}M_{\mathrm{n}}{ }^{c} \\
(\text { calcd) }\end{array}$ & \multicolumn{1}{c}{$\begin{array}{l}M_{\mathrm{n}}{ }^{d} \\
(\mathrm{GPC})\end{array}$} & \multicolumn{1}{c}{$\begin{array}{l}Ð \\
\left(M_{\mathrm{w}} / M_{\mathrm{n}}\right)\end{array}$} \\
\hline 1 & 10 & 7 & 5000 & 5400 & 1.40 \\
2 & 20 & 36 & 25900 & 16600 & 1.22 \\
3 & 30 & 78 & 56000 & 18100 & 1.34 \\
4 & 40 & 91 & 65500 & 25100 & 1.37 \\
5 & 50 & 93 & 67000 & 31400 & 1.32 \\
6 & 60 & 96 & 69100 & 55100 & 1.14
\end{tabular}

${ }^{a}$ All polymerization reactions were carried out in neat rac-lactide $(0.5 \mathrm{~g}), 125{ }^{\circ} \mathrm{C}$ with $[1]:[\mathrm{LA}]=1: 500 .{ }^{b}$ Determined by ${ }^{1} \mathrm{H}-\mathrm{NMR}$. ${ }^{c}$ Calculated from $([\mathrm{LA}] /[\mathrm{Mg}]) \times \%$ conv. $\times 144.13 \mathrm{~g} \mathrm{~mol}^{-1} \cdot{ }^{d}$ Molecular weights $\left(\mathrm{g} \mathrm{mol}^{-1}\right)$ determined by triple detection gel permeation chromatography (GPC) in tetrahydrofuran using a $\mathrm{d} n / \mathrm{d} c$ value of $0.049 \mathrm{~mL} \mathrm{~g}^{-1}$.

The conversion vs. time plot (Fig. S3 in ESI†) shows that polymerization starts once a homogenous melt is achieved (after 5 minutes at $125{ }^{\circ} \mathrm{C}$ ), the rate of conversion remains almost linear for the next $10 \mathrm{~min}$ and then accelerates for $5 \mathrm{~min}$ before returning to a constant rate. The discontinuity in conversion rate implies an induction period, which could be a result of dimer dissociation in order to form the active species. Solution polymerization kinetics studies (see below) are consistent with this theory. The MALDI-TOF mass spectra of the polymers obtained in the melt in the absence of $\mathrm{BnOH}$ showed the presence of both cyclic poly(rac-lactide) and linear chains terminated with $-\mathrm{OH}$ and carboxylic acid end groups (Fig. S4 and S5 in ESI ${ }^{\dagger}$ ).

\section{Mechanical properties of the polymers obtained under melt conditions}

Polymerizations were performed on a larger scale using $1.0 \mathrm{~g}$ (instead of $0.5 \mathrm{~g}$ ) of rac-lactide according to the conditions in 
Table 3 Polymerization of rac-lactide by 2 in toluene

\begin{tabular}{llrrrr}
\hline Entry $^{a}$ & {$[\mathrm{Mg}]:[\mathrm{LA}]:[\mathrm{ROH}]$} & Time $(\mathrm{min})$ & Conv. $^{b}(\%)$ & $M_{\mathrm{n}}{ }^{c}(\mathrm{calcd})$ & $M_{\mathrm{n}}{ }^{d}(\mathrm{GPC})$ \\
\hline 1 & $1: 100: 1(\mathrm{iPrOH})$ & 30 & 99 & 14300 & $5\left(M_{\mathrm{w}} / M_{\mathrm{n}}\right)$ \\
2 & $1: 100: 10(\mathrm{iPrOH})$ & 3 & 99 & 1400 & 400 \\
3 & $1: 100: 0$ & 210 & 100 & 14400 & 1.70 \\
4 & $1: 100: 1(\mathrm{BnOH})$ & 7 & 98 & 14100 & 46000 \\
5 & $1: 100: 2(\mathrm{BnOH})$ & 97 & 7200 & 13900 & 7100
\end{tabular}

${ }^{a}$ All polymerization reactions were carried out in toluene $(10 \mathrm{~mL})$ at $90{ }^{\circ} \mathrm{C} .{ }^{b}$ Determined by ${ }^{1} \mathrm{H}-\mathrm{NMR} .{ }^{c} \mathrm{Calculated}$ from $([\mathrm{LA}] /[\mathrm{Mg}] /[\mathrm{ROH}]) \times$

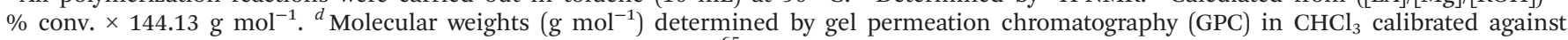
polystyrene standards using the Mark-Houwink correction of $0.58 .^{65}$

entries 3 and 4 of Table 1 to investigate the correlation between conversion and isolated yield. The scaled-up reactions improved the recovery of the polylactide after washing as determined by ${ }^{1} \mathrm{H}$ NMR. The physical appearance of the polymers obtained with and without added benzyl alcohol is significantly different as a result of the difference in polymer molecular weights obtained (Fig. S6 in ESI†). Without $\mathrm{BnOH}$, the polymer is obtained as a thin film whereas in the presence of alcohol a crystalline polymer results. Differential Scanning Calorimetry (DSC) and Thermogravimetric Analysis (TGA) were performed on these samples and revealed very similar thermal properties. The midpoint of the glass transition temperature taken from the third heating curve was $52.59{ }^{\circ} \mathrm{C}$ for the polymer obtained from entry 3 and $50.86{ }^{\circ} \mathrm{C}$ for entry 4 , which is expected given the polymer's much lower observed $M_{\mathrm{n}}$. TGA conducted with a ramp rate of $10{ }^{\circ} \mathrm{C} \mathrm{min}^{-1}$ showed the decomposition temperature of the polymer obtained in the absence of $\mathrm{BnOH}$ was $354.5^{\circ} \mathrm{C}$ and slightly higher $\left(356.7^{\circ} \mathrm{C}\right)$ for the polymer obtained in presence of $\mathrm{BnOH}$. Slower rates of $5{ }^{\circ} \mathrm{C} \mathrm{min}^{-1}$ resulted in slightly lower decomposition temperatures for both the polymers obtained with $\mathrm{BnOH}$ (onset at $340{ }^{\circ} \mathrm{C}$, end at $375{ }^{\circ} \mathrm{C}$ ) and without $\mathrm{BnOH}$ (onset at $344{ }^{\circ} \mathrm{C}$, end at $367^{\circ} \mathrm{C}$, see Fig. S7 and S8 in ESI $\dagger$ ). These decomposition temperatures are higher than expected, ${ }^{66}$ but they are similar to carboxylic acid terminated branched polymers reported by $\mathrm{S}$. H. Lee et $a{ }^{67}{ }^{67}$ It should be noted that the polymers used for thermal analysis were highly purified by precipitation, centrifugation, decanting of solvents, washing with cold methanol and drying by vacuum oven overnight at $40^{\circ} \mathrm{C}$.

Regarding polymer tacticity, the solvent-free (melt) ROP of rac-lactide using $\mathbf{1}$ gives an atactic microstructure of poly(rac-lactide). This is not surprising given the achiral ligands used in compounds $\mathbf{1}$ and 2 and the poor polymer $M_{\mathrm{n}}$ control. A representative ${ }^{1} \mathrm{H}\left\{{ }^{1} \mathrm{H}\right\}$-NMR spectrum of the methine resonances of poly(rac-lactide) is given in Fig. S9 in ESI. $\dagger$ Highly isotactic polylactide stereopolymers can be obtained solvent-free at $130{ }^{\circ} \mathrm{C}$ using salen aluminum alkoxides at a monomer/initiator molar ratio of 200 , but the reaction rates were very slow (95\% conversion after 2 days). ${ }^{68}$

\section{Ring opening polymerization in solution}

Polymerization at room temperature did not occur in either $\mathrm{CH}_{2} \mathrm{Cl}_{2}$ or THF with complexes 1 and 2 . However, upon heating to $90^{\circ} \mathrm{C}$ with 1 equivalent of isopropyl alcohol (iPrOH) as co-initiator complex 2 exhibited fast propagation in toluene achieving 98\% conversion in 12 minutes (Table 3, entry 1 and Fig. 2). Use of $\mathrm{iPrOH}$ accelerates the polymerization activity compared to using 2 alone, but gives lower than expected polymer molecular weights likely resulting from transesterification. Increasing the amount of $\mathrm{iPrOH}$ as co-initiator to 10 equivalents with respect to 2 resulted in faster reaction rate but much lower molecular weight and narrower dispersity (entry 2). The plot of conversion vs. time (Fig. 2) indicates an induction period of approximately 7 minutes before the onset of the expected conversion curve. This non-linearity is apparent when attempting to model the data using a first order kinetics plot over the whole reaction time (Fig. S10 in $\mathrm{ESI}_{\dagger} \dagger$ ). These observations can be explained if one considers the dimeric form of 2 in toluene as being inactive to ROP of raclactide. Hence, activation of the complex is achieved in the presence of co-initiator, possibly via formation of monomeric alcohol adducts. Once an active species is obtained, ROP proceeds quickly at $90{ }^{\circ} \mathrm{C}$, thus explaining the rapid increase in conversion after 7 minutes and effectively complete consumption of monomer after 12 minutes. This is consistent with the activity vs. $t$ plot (Fig. S11 in ESI $\dagger$ ), which shows the highest activity was observed between 9 and 15 min. NMR spectra following the reaction profile are given in Fig. S12 in ESI. $\dagger$

The influence of the co-initiator on polymerizations in toluene was investigated. The polymerization without a coinitiator (Table 3, entry 3) proceeded very slowly and any conversion of lactide was only observed after $30 \mathrm{~min}$ in toluene at

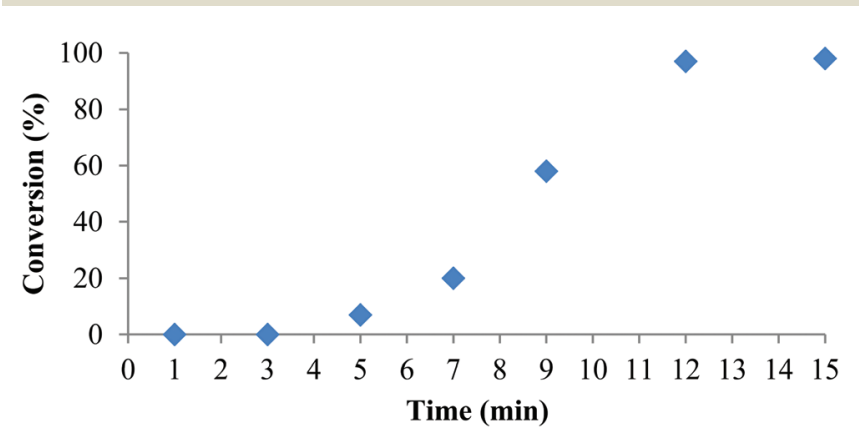

Fig. 2 Conversion (\%) vs. time for the ROP of rac-LA initiated by 2 under the conditions in Table 3, entry 1. 
$90{ }^{\circ} \mathrm{C}$, which is consistent with a slow initiation period. In the presence of $\mathrm{BnOH}$, however, the reaction proceeded very quickly and achieved 98\% conversion within 6 minutes (Table 3, entry 4). The polymerization demonstrates first order reaction profiles with respect to $[\mathrm{LA}]$ in either the presence or absence of $\mathrm{BnOH}$ (Fig. 3). The observed rate constant, $k_{\mathrm{obs}}$, in the presence of $\mathrm{BnOH}$ was $0.828 \mathrm{~min}^{-1}$ whereas in the absence of $\mathrm{BnOH}$ was $9.87 \times 10^{-2} \mathrm{~min}^{-1}$. When the concentration of $\mathrm{BnOH}$ was doubled (Table 3 , entry 5), the molecular weight of the polymer decreased by half, which suggests a well-behaved immortal ROP with rapid, reversible chain transfer between growing PLA fragments and dormant hydroxyl-terminated polylactide chains. ${ }^{69,70}$

\section{Mechanistic proposal}

Without addition of exogenous alcohol, the ROP of LA is slower in solution than when the alcohol co-initiator is

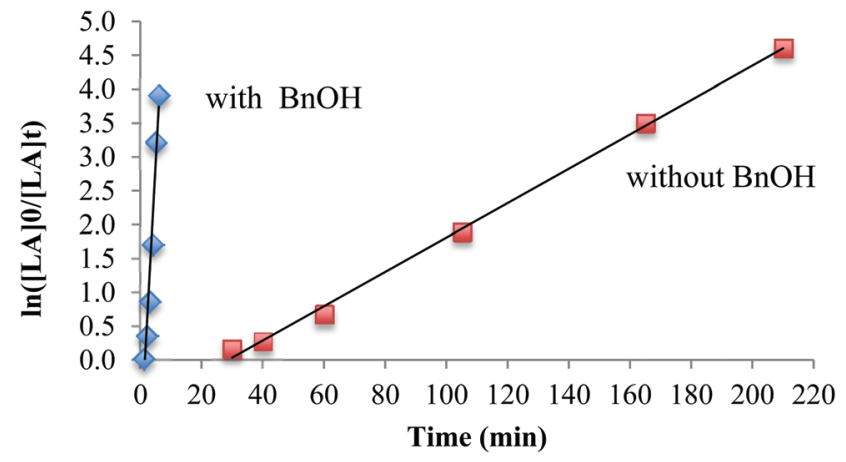

Fig. 3 Plot of $\ln [\mathrm{LA}]_{0} /[\mathrm{LA}]_{t}$ vs. $t,[\mathrm{LA}]_{0} /[\mathrm{Mg}]_{0}=100$, in toluene at $90^{\circ} \mathrm{C}$ according to the conditions in Table 3, entries 3 and 4. present. Initiation by nucleophilic attack of the phenolate ligand on the monomer has been observed in related lithiumphenolate complexes. ${ }^{10,44,69}$ In melt polymerization, however, there is no significant loss of control of the polymerization when conducted in the absence of alcohol co-initiator. The observation in the MALDI-TOF mass spectrum of cyclic polylactide alongside acyclic polymer possessing carboxylic acid and hydroxyl end groups (resulting from hydrolytic quenching of polymerization with acidified methanol) is consistent with phenolate-initiated ROP (Scheme 2).

The mechanism of polymerization and the role of the alcohol co-initiator require closer examination, particularly since the majority of binary systems (employing a Lewis acidic metal site and an added alcohol as initiators) hypothesize coordination-insertion mechanisms. Carpentier, Sarazin and co-workers suggest that activated monomer mechanisms should not be excluded and have performed elegant studies of alkali aminoether-phenolate complexes that provide strong evidence that this mechanism at play under living or immortal ROP conditions of $\mathrm{L}-\mathrm{LA}{ }^{69}$

Preliminary stoichiometric studies by ${ }^{1} \mathrm{H}$ NMR spectroscopy of reactions involving complex 2 , rac-LA and $\mathrm{BnOH}$ were conducted in toluene- $\mathrm{d}_{8}$ at $363 \mathrm{~K}$, i.e. the conditions employed in solution ROP catalysis shown in Table 3 . The reaction of a $1: 1$ ratio (per $\mathrm{Mg}$ centre) of 2 and $\mathrm{BnOH}$ was followed by ${ }^{1} \mathrm{H}$ NMR at $363 \mathrm{~K}$. After 10 minutes at this temperature, in addition to those of complex 2 alone, new resonances were observed consistent with monomeric $\mathrm{Mg}$ compounds (see Fig. S14 ESI $\dagger$ for ${ }^{1} \mathrm{H}$ NMR spectra). It is not unequivocal whether the $\mathrm{BnOH}$ is coordinated to the metal centre since the benzyl methylene peak is slightly broadened at this temperature, possibly from an exchange process as suggested by the continued presence

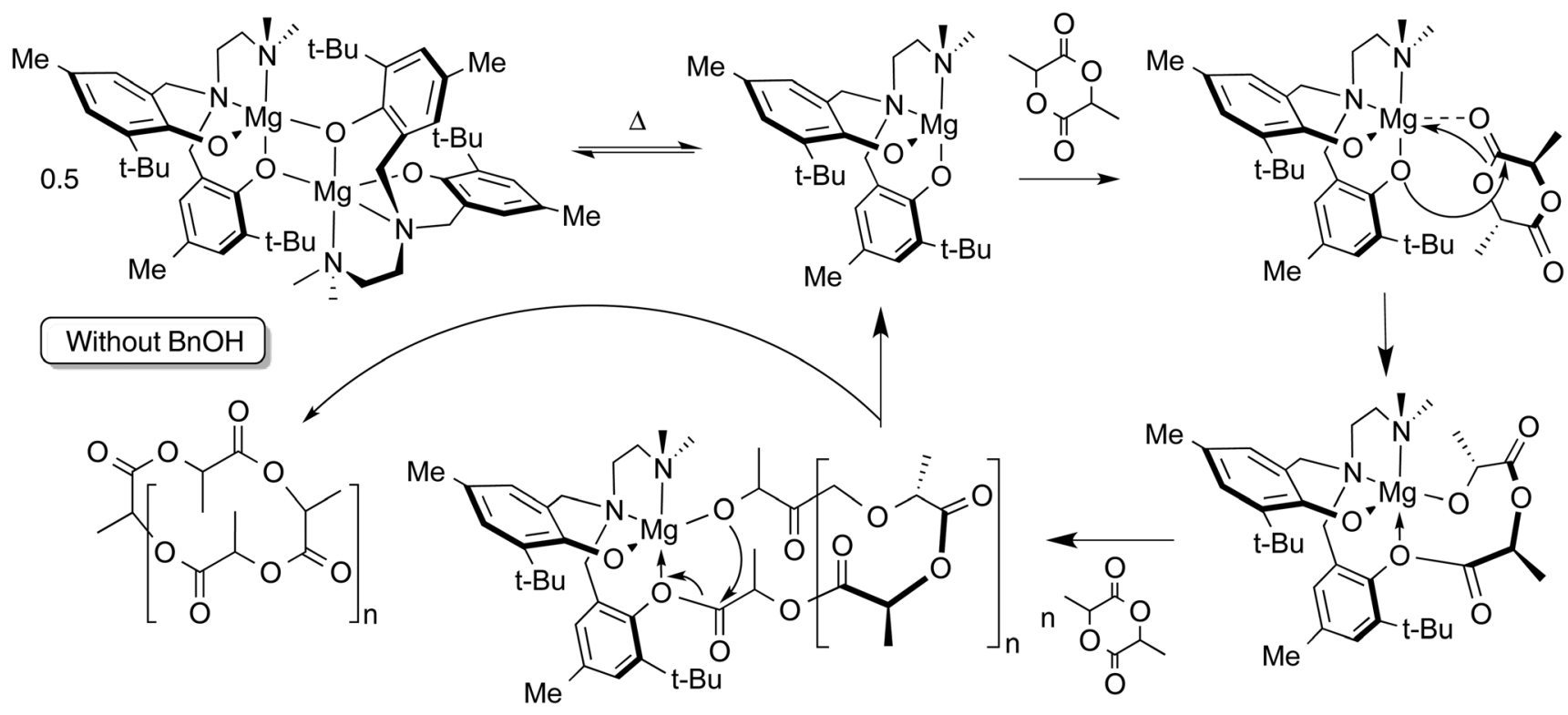

Scheme 2 Proposed mechanism for ROP of LA by 2 without added alcohol co-initiator. Generation of cyclic polymer is shown, but hydroxyl or carboxylic acid end groups may be obtained by protonolysis. 

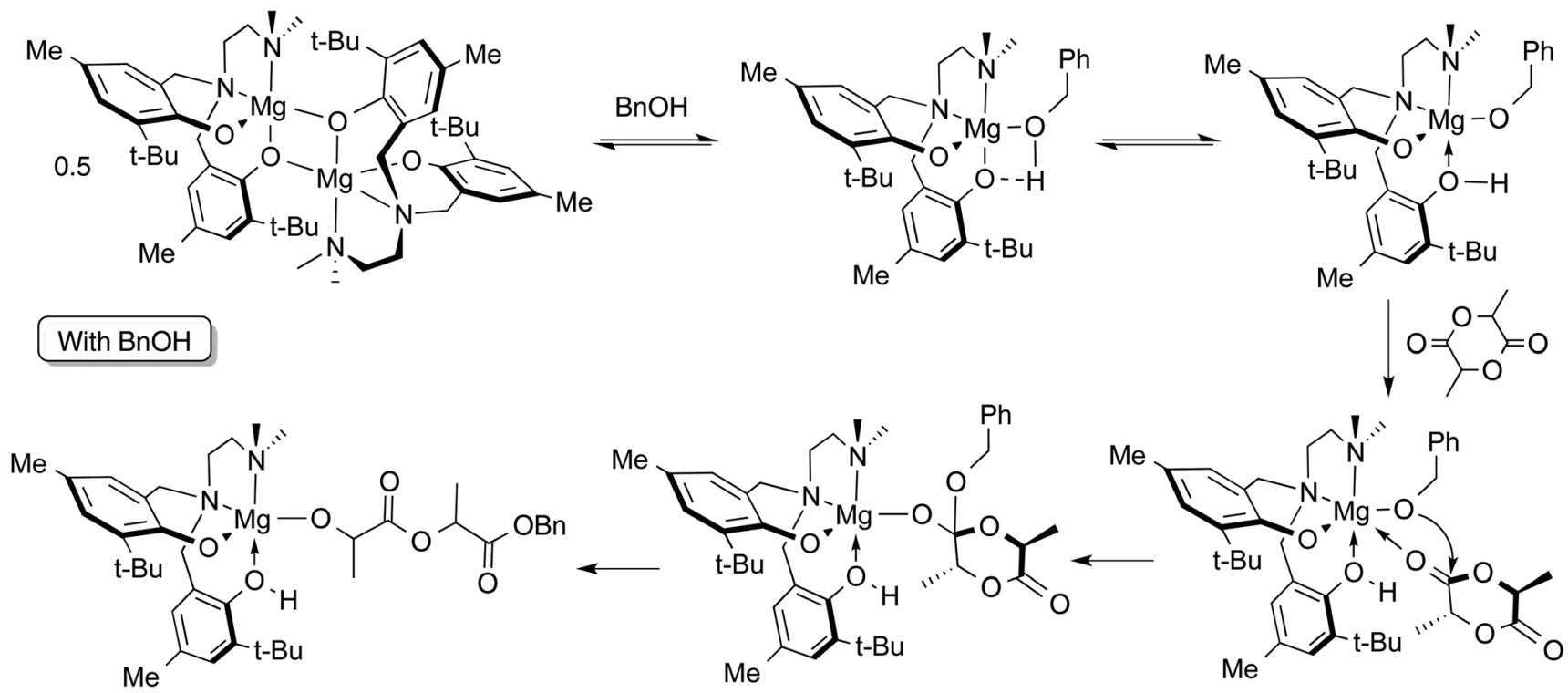

Scheme 3 Proposed mechanism for ROP of LA by 2 with benzyl alcohol co-initiator.

of dimer in the spectrum. Also, a very small peak at $9.19 \mathrm{ppm}$ could be observed upon expansion of the region of the spectrum, suggesting that the presence of protonated ligand, $\mathrm{H}_{2}[\mathbf{L} 2]$ is negligible.

The reaction of a $1: 1: 1$ mixture of $r a c-\mathrm{LA}, 2$ and $\mathrm{BnOH}$ was monitored under the same conditions. Within 10 minutes at $363 \mathrm{~K}$ the product of lactide ring-opening, benzyl-2-((2-hydroxypropanoyl)oxy)propanoate or its deprotonated alkoxide form, was observed. It is possible that the ring-opened lactide remains coordinated to the $\mathrm{Mg}$ site, since a phenolic $-\mathrm{OH}$ resonance is observable at $9.22 \mathrm{ppm}$ indicating protonation of a phenolate oxygen. The proposed mechanism is shown in Scheme 3. Based on these observations, an activated monomer mechanism may be occurring, but further investigation is needed.

\section{Conclusions}

Magnesium amine-bis(phenolate) compounds 1 and 2 showed catalytic activity for the ROP of rac-lactide both in toluene solutions and solvent-free (melt) to give atactic poly(rac-lactide). Kinetic studies showed that conversion of rac-lactide is essentially complete within 60 minutes in the melt at $125{ }^{\circ} \mathrm{C}$, although the resulting polymers exhibit broad dispersities. Solution polymerization studies in toluene at $90{ }^{\circ} \mathrm{C}$ indicate long initiation periods in the absence of an alcohol coinitiator, but rapid initiation when a suitable co-initiator is used. Complex 2 proved to be an efficient initiator in solution at $90{ }^{\circ} \mathrm{C}$ with a $[\mathrm{LA}]:[\mathrm{Mg}]$ ratio of $100: 1$ regardless of whether a co-initiator was used or not. Without a co-initiator an initiation period of $\sim 30 \mathrm{~min}$ was observed, after which time the propagation showed a slow first order reaction profile with respect to rac-lactide concentration and effectively complete conversion within 210 minutes. The polymerization was accelerated significantly by the addition of a co-initiator, either iPrOH or BnOH. The highest activity was observed for [LA]: $[\mathrm{Mg}]:[\mathrm{BnOH}]$ ratios of $100: 1: 1$ at $90{ }^{\circ} \mathrm{C}$ in toluene giving $177.3 \mathrm{~kg}$ of $\mathrm{rac}$-PLA per mol Mg per $\mathrm{h}\left(k_{\mathrm{obs}}=1.38 \times 10^{-2} \mathrm{~s}^{-1}\right)$. Preliminary mechanistic studies support an activated monomer pathway, but more detailed studies are ongoing.

\section{Experimental}

\section{General experimental conditions}

Unless otherwise stated, all manipulations were performed under an atmosphere of dry, oxygen-free nitrogen by means of standard Schlenk techniques or using an MBraun Labmaster DP glove box. Anhydrous THF was distilled from sodium benzophenone ketyl under nitrogen. Isopropyl alcohol was dried over calcium oxide, then distilled under nitrogen. Toluene was purified by an MBraun Manual Solvent Purification System. Reagents were purchased either from Aldrich or Alfa Aesar and used without further purification. Rac-lactide was purchased from Aldrich or Alfa Aesar and dried over sodium sulphate in THF, recrystallized and stored under an inert atmosphere prior to use. Benzyl alcohol was purchased from Alfa Aesar and dried over activated $4 \AA$ A molecular sieves, distilled under reduced pressure and stored under nitrogen in an ampule prior to use.

\section{Instrumentation}

MALDI-TOF MS was performed using an Applied Biosystems 4800 MALDI TOF/TOF Analyzer equipped with a reflectron, delayed ion extraction and high performance nitrogen laser (200 Hz operating at $355 \mathrm{~nm}$ ). Samples were prepared in the glove box and sealed under nitrogen in a Ziploc@ bag for trans- 
port to the instrument. Anthracene was used as the matrix for compounds 1 and 2 and 2,5-dihydroxybenzoic acid (DHBA) was used as the matrix for the polymers. The matrix was dissolved in THF at a concentration of $10 \mathrm{mg} \mathrm{mL}^{-1}$. Polymer was dissolved in THF at approximately $1 \mathrm{mg} \mathrm{mL}^{-1}$. The matrix and polymer solutions were mixed together at ratios of 5 to 1,4 to 1 or 3 to $1 ; 1 \mu \mathrm{L}$ of this was spotted on the MALDI plate and left to dry. Images of mass spectra were prepared using mMass $^{\mathrm{TM}}$ software (http://www.mmass.org).

GPC analysis was performed either in $\mathrm{CHCl}_{3}$ on a Viscotek VE 2001 GPCMax at $35{ }^{\circ} \mathrm{C}$ equipped with a Viscotek VE 3580 Refractive Index Detector or in THF at $25^{\circ} \mathrm{C}$ on a Wyatt Triple Detection (triple angle light scattering, viscometry and refractive index) system with Agilent 2600 series sample and solvent handling. The Viscotek system used two Phenogel $5 \mu$ Linear Mixed Bed $300 \times 4.60 \mathrm{~mm}$ columns whereas the Wyatt system used two Phenogel $10^{3} \AA 300 \times 4.60 \mathrm{~mm}$ columns. Samples were prepared at a concentration of $2 \mathrm{mg} \mathrm{mL}^{-1}$ in $\mathrm{CHCl}_{3}$ and left to equilibrate for $\sim 2 \mathrm{~h}$. The samples were filtered through syringe filters before analysis and eluted with HPLC grade sol-

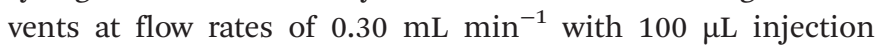
volumes. For conventional calibration, six polystyrene standards (Viscotek) were used in making the calibration curve, bracketing molecular ranges from 1050 to 400000 Da. A correction factor of 0.58 was used to calculate the $M_{\mathrm{n}}$ value. $^{65}$

NMR spectra were recorded at $300 \mathrm{MHz}$ for ${ }^{1} \mathrm{H}$ and $75.5 \mathrm{MHz}$ for ${ }^{13} \mathrm{C}$ or at $500 \mathrm{MHz}$ for ${ }^{1} \mathrm{H}$ NMR kinetic studies. $\mathrm{CDCl}_{3}, \mathrm{C}_{6} \mathrm{D}_{6}, \quad$ DMSO- $\mathrm{d}_{6}$ were purchased from Cambridge Isotope Laboratories and pyridine- $\mathrm{d}_{5}$ from Aldrich. All deuterated solvents except for DMSO- $\mathrm{d}_{6}$ used in the analysis of the magnesium complexes were dried over calcium hydride $\left(\mathrm{CDCl}_{3}\right.$ and pyridine- $\left.\mathrm{d}_{5}\right)$ or sodium/potassium alloy $\left(\mathrm{C}_{6} \mathrm{D}_{6}\right)$, vacuum transferred and stored under nitrogen in ampules fitted with Teflon valves. Elemental analyses were performed at Guelph Chemical Laboratories, Guelph, Ontario, Canada.

Thermogravimetric analysis (TGA) was performed with a TA Instruments Q500. Samples (4-15 mg) were loaded onto a platinum pan and subjected to a dynamic high-resolution scan, with an initial heating rate of 5 or $10{ }^{\circ} \mathrm{C} \mathrm{min}^{-1}$. Each sample was heated from room temperature to $600{ }^{\circ} \mathrm{C}$. Glass transition $\left(T_{\mathrm{g}}\right)$ temperatures were measured using a Mettler Toledo DSC 1 STAR $^{\mathrm{e}}$ System equipped with a Julabo FT 100 immersion cooling system, using R1150 refrigerant in an EtOH bath with a working range of -100 to $+20{ }^{\circ} \mathrm{C}$. Samples ( $\sim 5 \mathrm{mg}$ ) were weighed into $40 \mu \mathrm{L}$ aluminum pans and subjected to three heating cycles. The first heating cycle consisted of heating from 0 to $100{ }^{\circ} \mathrm{C}$ at a rate of $10^{\circ} \mathrm{C} \mathrm{min}^{-1}$, held for $2 \mathrm{~min}$ at $100{ }^{\circ} \mathrm{C}$ and then cooled back to $0{ }^{\circ} \mathrm{C}$ at $10^{\circ} \mathrm{C} \mathrm{min}^{-1}$. The sample was held at this temperature for $2 \mathrm{~min}$ and subjected to a two heating cycles from 0 to $190{ }^{\circ} \mathrm{C}$ at a rate of $10{ }^{\circ} \mathrm{C} \min ^{-1}$.

\section{Synthesis of compounds}

$\mathbf{H}_{2}$ [L1]. Aminomethylpyridine (6.65 g, $\left.0.0615 \mathrm{~mol}\right)$ was slowly added to a vigorously stirred mixture of 3-tert-butyl-5hydroxyanisole $(22.17 \mathrm{~g}, \quad 0.123 \mathrm{~mol})$ and formaldehyde
(9.16 $\mathrm{mL}$ of a $37 \%$ aqueous solution, $0.123 \mathrm{~mol}$ ) in deionized water $(100 \mathrm{~mL})$ in a round bottom flask equipped with a magnetic stir bar. This mixture was heated to reflux and stirred overnight. Upon cooling, a large quantity of white solid formed. The solvent was decanted and the solid was washed with cold methanol then recrystallized from a chloroformmethanol solvent mixture to give a white crystalline powder (25.06 g, 82\% yield). Anal. Calcd For $\mathrm{C}_{30} \mathrm{H}_{40} \mathrm{~N}_{2} \mathrm{O}_{4}$ : C 73.14, $\mathrm{H}$ 8.18, N 5.69. Found: $\mathrm{C} 72.88, \mathrm{H} 7.90, \mathrm{~N}$ 5.53. ${ }^{1} \mathrm{H}$ NMR (300 MHz, $298 \mathrm{~K}, \mathrm{CDCl}_{3}, \delta$ ): 10.30 (br s, OH, 2H), 8.69 (ddd, $\left.{ }^{3} J_{\mathrm{HH}}=5.03 \mathrm{~Hz},{ }^{4} J_{\mathrm{HH}}=1.79,{ }^{5} J_{\mathrm{HH}}=0.93 \mathrm{~Hz}, \mathrm{Py}: \mathrm{NCH}, 1 \mathrm{H}\right), 7.70$ $\left(\mathrm{ddd},{ }^{3} J_{\mathrm{HH}}=7.69 \mathrm{~Hz},{ }^{3} J_{\mathrm{HH}}=7.69 \mathrm{~Hz},{ }^{4} J_{\mathrm{HH}}=1.79 \mathrm{~Hz}, \mathrm{Py}:\right.$ $\mathrm{NCHCH}, 1 \mathrm{H}), 7.29\left(\mathrm{ddd},{ }^{3} J_{\mathrm{HH}}=7.69 \mathrm{~Hz},{ }^{4} J_{\mathrm{HH}}=5.01 \mathrm{~Hz},{ }^{5} J_{\mathrm{HH}}=\right.$ $1.05 \mathrm{~Hz}$, Py: NCHCHCH, 1H), $7.12\left(\mathrm{dt},{ }^{3} J_{\mathrm{HH}}=7.80 \mathrm{~Hz},{ }^{4} J_{\mathrm{HH}}=\right.$ $1.05 \mathrm{~Hz}, \mathrm{Py}: \mathrm{NCCH}, 1 \mathrm{H}), 6.83$ (d, ${ }^{4} J_{\mathrm{HH}}=3.08 \mathrm{~Hz}, \mathrm{Ar}: \mathrm{CHCCH}_{2} \mathrm{~N}$, $2 \mathrm{H}), 6.51\left(\mathrm{~d},{ }^{4} J_{\mathrm{HH}}=3.06 \mathrm{~Hz}, \mathrm{Ar}: \mathrm{CHCCMe}_{3}, 2 \mathrm{H}\right), \quad 3.80$ (s, $\left.\mathrm{NCH}_{2} \mathrm{Py}, 2 \mathrm{H}\right), 3.78$ (s, NCH $\left.\mathrm{N}_{2} \mathrm{Ar}, 4 \mathrm{H}\right), 3.75$ (s, OMe, 6H), 1.40 $\left(\mathrm{s}, \mathrm{CMe}_{3}, 18 \mathrm{H}\right) .{ }^{13} \mathrm{C}\left\{{ }^{1} \mathrm{H}\right\} \mathrm{NMR}\left(75.5 \mathrm{MHz}, \mathrm{CDCl}_{3}, 298 \mathrm{~K}, \delta\right)$ : $155.99(\mathrm{COH}) ; 151.96$ (Ar: $C \mathrm{OMe}) 150.38\left(\mathrm{Ar}: \mathrm{CCH}_{2} \mathrm{~N}\right), 148.37$ (Py: NCCH), 139.06 (Py: NC), 137.68 (Py: NCCHCH), 124.18 (Py: $\mathrm{NCH}$ ), 122.85 (Ar: $C \mathrm{CMe}_{3}$ ); 122.81 (Py: $\mathrm{NCHCH}$ ), 113.72 (Ar: $\mathrm{CHCCH}_{2} \mathrm{~N}$ ); 112.54 (Ar: $\left.\mathrm{CHCCMe}_{3}\right) ; 56.44\left(\mathrm{CH}_{2} \mathrm{Py}\right) ; 55.91$ $(\mathrm{OMe}) ; 55.12\left(\mathrm{NCH}_{2} \mathrm{Ar}\right), 35.28\left(\mathrm{CMe}_{3}\right), 29.66\left(\mathrm{CMe}_{3}\right)$.

$\mathbf{H}_{2}$ [L2]. $N, N$-Dimethylethylenediamine $(5.45 \mathrm{~g}, 61.8 \mathrm{mmol})$ was slowly added to a vigorously stirred mixture of 2-tert-butyl4-methylphenol (20.23 g, $123 \mathrm{mmol})$ and formaldehyde (10.0 $\mathrm{mL}$ of a $37 \%$ aqueous solution, $0.123 \mathrm{~mol}$ ) in deionized water $(100 \mathrm{~mL})$ in a round bottom flask equipped with a magnetic stir bar. The mixture was heated to reflux and stirred for approximately 24 hours, at which point a large amount of orange-brown solid had formed. The mixture was decanted and the remaining solid residue was washed with ice-cold methanol to yield a white powder. Recrystallization from chloroform produced analytically pure product (yield: $23.8 \mathrm{~g}$, $88 \%$ ). Spectroscopic characterization was consistent with that previously reported. ${ }^{53}$

1: $2.46 \mathrm{~g}$ (5.00 mmol) of $\mathrm{H}_{2}[\mathbf{L 1}]$ was dissolved in $100 \mathrm{~mL}$ of toluene and cooled to $-78{ }^{\circ} \mathrm{C}$. To this solution was added $5.0 \mathrm{mmol}$ of $\mathrm{MgBu}_{2}(5.0 \mathrm{~mL}$ of a $1.0 \mathrm{M}$ solution in heptane) via syringe. The solution was warmed to room temperature and stirred overnight. Volatiles were removed in vacuo to yield a pale yellow powder. Yield $=2.42 \mathrm{~g}$ (94\%). Anal. calc'd for $\mathrm{C}_{30} \mathrm{H}_{38} \mathrm{MgN}_{2} \mathrm{O}_{4}$ : C 69.97, $\mathrm{H}$ 7.44, N 5.44. Found: C 69.26, H 7.17, $\mathrm{N} 5.13$. The lower than expected \%C is attributed to a $5-10 \%$ contamination by $\mathrm{MgO}$ or $\mathrm{Mg}(\mathrm{OH})_{2}$ (e.g. anal. calc'd for $\mathrm{C}_{30} \mathrm{H}_{38} \mathrm{MgN}_{2} \mathrm{O}_{4}\left(\mathrm{MgO}_{2} \mathrm{H}_{2}\right)_{0.05}$ : C 69.58, H 7.42, N 5.41. ${ }^{1} \mathrm{H}$ NMR (300 MHz, $298 \mathrm{~K}, \mathrm{DMSO}_{6}, \delta$ ): 8.49 (d, ${ }^{3} J_{\mathrm{HH}}=4.43 \mathrm{~Hz}$, Py: $\mathrm{NCH}, 1 \mathrm{H}) ; 7.68\left(\mathrm{td},{ }^{3} J_{\mathrm{HH}}=7.62 \mathrm{~Hz},{ }^{4} J_{\mathrm{HH}}=1.51 \mathrm{~Hz}, \mathrm{Py}: \mathrm{NCHCH}\right.$, $1 \mathrm{H}$ ); 7.21 (dd, coupling constants could not be determined because of the overlapping residual toluene peaks, Py: $\mathrm{NCHCHCH}, 1 \mathrm{H}) ; 7.06$ (d, $\left.{ }^{3} J_{\mathrm{HH}}=7.8 \mathrm{~Hz}, \mathrm{Py}: \mathrm{NCCH}, 1 \mathrm{H}\right) ; 6.44$ $\left(\mathrm{d},{ }^{4} \mathrm{~J}_{\mathrm{HH}}=3.23 \mathrm{~Hz}, \mathrm{Ar}: \mathrm{CHCCH}_{2} \mathrm{~N}, 2 \mathrm{H}\right) ; 6.38\left(\mathrm{~d},{ }^{4} J_{\mathrm{HH}}=3.23 \mathrm{~Hz}\right.$, Ar: $\left.\mathrm{CHCCMe}_{3}, 2 \mathrm{H}\right) ; 3.76\left(\mathrm{~d},{ }^{3} J_{\mathrm{HH}}=11.65 \mathrm{~Hz}, \mathrm{NCH}_{2} \mathrm{Ar}, 2 \mathrm{H}\right) ; 3.58$ (s, $\left.\mathrm{NCH}_{2} \mathrm{Py}, 2 \mathrm{H}\right) ; 3.55$ (s. $\left.\mathrm{OCH}_{3}, 6 \mathrm{H}\right) ; 3.15$ (d, ${ }^{3} \mathrm{~J}_{\mathrm{HH}}=11.72 \mathrm{~Hz}$, $\left.\mathrm{NCH}_{2} \mathrm{Ar}, 2 \mathrm{H}\right) ; 1.29$ (s, C(CH $\left.)_{3}, 18 \mathrm{H}\right) .{ }^{13} \mathrm{C}\left\{{ }^{1} \mathrm{H}\right\} \mathrm{NMR}(75.5 \mathrm{MHz}$, $298 \mathrm{~K}, \mathrm{DMSO}_{6}, \delta$ ): 160.71 (COMg); 158.04 (COMe); 148.60 
(Ar: $\mathrm{CCH}_{2} \mathrm{~N}$ ); 145.35 (Py: $\left.\mathrm{NCCH}\right) ; 138.46$ (Py: NC); 136.66 (Py: $\mathrm{NCCHCH}$ ); 130.38 (Py: NCHCH); 122.69 (Py: NCH); 122.03 (Ar: $\left.\mathrm{CCMe}_{3}\right) ; 113.46\left(\mathrm{Ar}: \mathrm{CHCCH}_{2} \mathrm{~N}\right) ; 112.94\left(\mathrm{Ar}: \mathrm{CHCCMe}_{3}\right) ; 60.68$ $\left(\mathrm{CH}_{2} \mathrm{Py}\right) ; 56.10\left(\mathrm{CH}_{2} \mathrm{Ar}\right) ; 55.69(\mathrm{OMe}) ; 34.54 \quad\left(\mathrm{CMe}_{3}\right) ; 29.34$ $\left(\mathrm{CMe}_{3}\right) . \mathrm{MS}$ (MALDI-TOF) $m / z$ (\%, ion): $514.26\left(58,[\mathrm{M}]^{+}\right)$; $1028.50\left(100,[\mathrm{M}]_{2}^{+}\right)$.

2: $2.21 \mathrm{~g}(5.0 \mathrm{mmol})$ of $\mathrm{H}_{2}\left[\mathbf{L}_{2}\right]$ was dissolved in $70 \mathrm{~mL}$ of toluene and cooled to $-78{ }^{\circ} \mathrm{C}$. To this solution was added $5.0 \mathrm{mmol}$ of $\mathrm{MgBu}_{2}(5.0 \mathrm{~mL}$ of a $1.0 \mathrm{M}$ solution in heptane) via syringe, forming a bright yellow solution. The solution was warmed to room temperature and stirred overnight, upon which a large amount of white precipitate formed within a colourless solution. Volatiles were removed in vacuo, yielding an analytically pure white powder. Yield $=2.29 \mathrm{~g}(99 \%)$. Recrystallization from toluene at $-35{ }^{\circ} \mathrm{C}$ afforded colourless crystals. Anal. calc'd for $\mathrm{C}_{34} \mathrm{H}_{54} \mathrm{MgN}_{2} \mathrm{O}_{2}$ : C 72.64, $\mathrm{H}$ 9.14, N 6.05. Found: C 72.38, H 9.09, N 6.22. ${ }^{1} \mathrm{H}$ NMR (300 MHz, $298 \mathrm{~K}$, $\left.\mathrm{C}_{6} \mathrm{D}_{6}, \delta\right): 7.29(\mathrm{~m}, \mathrm{Ar}, 4 \mathrm{H}) ; 6.80\left(\mathrm{~d},{ }^{4} J_{\mathrm{HH}}=2.35 \mathrm{~Hz}, \mathrm{Ar}, 2 \mathrm{H}\right) ; 6.69$ $\left(\mathrm{d},{ }^{4} J_{\mathrm{HH}}=2.30, \mathrm{Ar}, 2 \mathrm{H}\right) ; 4.84\left(\mathrm{~d},{ }^{2} J_{\mathrm{HH}}=12.01 \mathrm{~Hz}, \operatorname{Ar}-\mathrm{CH}(\mathrm{H})-\mathrm{N}\right.$, $2 \mathrm{H}) ; 4.63\left(\mathrm{~d},{ }^{2} J_{\mathrm{HH}}=12.41 \mathrm{~Hz}, \operatorname{Ar}-\mathrm{CH}(\mathrm{H})-\mathrm{N}, 2 \mathrm{H}\right) ; 2.97\left(\mathrm{~d},{ }^{2} J_{\mathrm{HH}}=\right.$ $12.38 \mathrm{~Hz}, \mathrm{Ar}-\mathrm{CH}(\mathrm{H})-\mathrm{N}, 2 \mathrm{H}) ; 2.63\left(\mathrm{~d},{ }^{2} J_{\mathrm{HH}}=12.06 \mathrm{~Hz}, \mathrm{Ar}-\mathrm{CH}-\right.$ (H)-N, 2H); 2.00-2.70 (br, $\left.\mathrm{CH}_{2} \mathrm{NMe}_{2}, 4 \mathrm{H}\right) ; 2.35$ (s, NMe $2,6 \mathrm{H}$ ); 2.31 (s, NMe $2,6 \mathrm{H}$ ); 1.05-1.70 (br, $\left.\mathrm{CH}_{2} \mathrm{CH}_{2} \mathrm{NMe}_{2}, 4 \mathrm{H}\right) ; 1.69$ (s, $\mathrm{CMe}_{3}, 18 \mathrm{H}$ ); 1.65 (s, ArMe, 6H); 1.59 (s, ArMe, 6H); 1.29 (s, $\left.\mathrm{CMe}_{3}, 18 \mathrm{H}\right) .{ }^{13} \mathrm{C}\left\{{ }^{1} \mathrm{H}\right\}$ NMR $\left(75.5 \mathrm{MHz}, 298 \mathrm{~K}, \mathrm{C}_{6} \mathrm{D}_{6}, \delta\right): 164.59$ $(C-\mathrm{O}) ; 160.09$ (C-O); 137.80, 136.95, 130.13, 129.61, 128.92, 128.06, 128.74, 125.55, 123.01, 119.89 (All Ar); $65.49\left(\mathrm{ArCH}_{2}\right)$; $64.48\left(\mathrm{ArCH}_{2}\right) ; 60.54\left(\mathrm{CH}_{2} \mathrm{CH}_{2} \mathrm{NMe}_{2}\right) ; 48.69\left(\mathrm{CH}_{2} \mathrm{NMe}_{2}\right) ; 47.55$ $\left(\mathrm{NMe}_{2}\right) ; 47.42\left(\mathrm{NMe}_{2}\right) ; 35.12\left(\mathrm{CMe}_{3}\right) ; 34.77\left(\mathrm{CMe}_{3}\right) ; 32.82$ $\left(\mathrm{CMe}_{3}\right) ; 30.34\left(\mathrm{CMe}_{3}\right) ; 20.98$ (ArMe); 20.90 (ArMe). ${ }^{1} \mathrm{H}$ NMR $\left(300 \mathrm{MHz}, 298 \mathrm{~K}\right.$, pyridine $\left.-\mathrm{d}_{5}, \delta\right): 7.35\left(\mathrm{~d},{ }^{4} J_{\mathrm{HH}}=2.45 \mathrm{~Hz}, \mathrm{Ar}\right.$, $2 \mathrm{H}) ; 6.92\left(\mathrm{~d},{ }^{4} J_{\mathrm{HH}}=2.51 \mathrm{~Hz}, \mathrm{Ar}, 2 \mathrm{H}\right) ; 4.04\left(\mathrm{~d},{ }^{2} J_{\mathrm{HH}}=12.49, \mathrm{Ar}-\right.$ $\mathrm{CH}(\mathrm{H})-\mathrm{N}, 2 \mathrm{H}) ; 3.11\left(\mathrm{~d},{ }^{2} J_{\mathrm{HH}}=12.51 \mathrm{~Hz}, \mathrm{Ar}-\mathrm{CH}(\mathrm{H})-\mathrm{N}, 2 \mathrm{H}\right) ; 2.75$ (br, $\left.\mathrm{CH}_{2} \mathrm{NMe}_{2}, 2 \mathrm{H}\right) ; 2.40$ (s, NMe $2,6 \mathrm{H}$ ); 2.23 (br, $\mathrm{CH}_{2} \mathrm{CH}_{2} \mathrm{NMe}_{2}$, 2H); 1.97 (s, ArMe, 6H); 1.75 (s, $\left.\mathrm{CMe}_{3}, 18 \mathrm{H}\right) .{ }^{13} \mathrm{C}\left\{{ }^{1} \mathrm{H}\right\}$ NMR (75.5 MHz, $298 \mathrm{~K}$, pyridine- $\left.\mathrm{d}_{5}, \delta\right): 167.80(C-\mathrm{O})$; 138.71, 132.41, 130.65, 130.08, 126.64 (All Ar); $66.88 \quad\left(\mathrm{ArCH}_{2}\right) ; 61.54$ $\left(\mathrm{CH}_{2} \mathrm{CH}_{2} \mathrm{NMe}_{2}\right) ; 51.27\left(\mathrm{CH}_{2} \mathrm{NMe}_{2}\right) ; 49.51\left(\mathrm{NMe}_{2}\right) ; 37.24\left(\mathrm{CMe}_{3}\right)$; $32.43\left(\mathrm{CMe}_{3}\right) ; 23.05\left(\mathrm{CMe}_{3}\right)$. MS (MALDI-TOF) $\mathrm{m} / z$ (\%, ion): $462.25\left(100,[\mathrm{M}]^{+}\right) ; 924.52\left(3,[\mathrm{M}]_{2}^{+}\right)$.

\section{Polymerization procedure}

Melt polymerization. A representative polymerization with a 500:1 [rac-lactide]:[1] ratio was carried out with $500 \mathrm{mg}$ $(3.47 \mathrm{mmol}) \mathrm{rac}$-lactide and $3.57 \mathrm{mg}\left(6.93 \times 10^{-3} \mathrm{mmol}\right)$ of complex 1 weighed into a $10 \mathrm{~mL}$ scintillation vial equipped with a small stir bar in the glove box. The closed vial was taken out of the glove box and placed into an aluminum block vial holder, which was pre-heated on a hotplate to $125^{\circ} \mathrm{C}$. A typical polymerization was run for 100 minutes. The vial was then placed in an ice bath to halt the reaction and solidify the polymer. The solids were dissolved in dichloromethane or chloroform and the polymer was precipitated with acidified methanol. Centrifugation was applied where needed for better separation of the solids. Solvents were decanted and the white solids (either crystalline or thin film-like) were dried in vacuo followed by drying in a vacuum oven at $40^{\circ} \mathrm{C}$ overnight.

Solution polymerization. The appropriate amount of complex 1 or 2 and alcohol (iPrOH or $\mathrm{BnOH}$ ) were placed in an ampule equipped with a PTFE valve. A second ampule was prepared containing a stir bar and the required amount of monomer and toluene $(7.50 \mathrm{~mL})$. Both ampules were heated to $90{ }^{\circ} \mathrm{C}$ for $\sim 30 \mathrm{~min}$, after which time the lactide solution was transferred by cannula to the complex mixture. Timing of the reaction began when all the lactide was transferred. An aliquot of the reaction mixture was taken for ${ }^{1} \mathrm{H}$ NMR analysis at certain time intervals. When the presence of monomer was no longer apparent by ${ }^{1} \mathrm{H}$ NMR, volatiles were removed in vacuo and the solid residue was dissolved in $\mathrm{CH}_{2} \mathrm{Cl}_{2}$ and precipitated using cold methanol. Solvents were decanted and the white solids were dried in vacuo followed by drying in a vacuum oven at $40^{\circ} \mathrm{C}$ overnight.

\section{Acknowledgements}

Financial support was provided by the Canada Foundation for Innovation (CFI), Newfoundland and Labrador Research Development Corporation, the Natural Sciences and Engineering Research Council (NSERC) of Canada and Memorial University of Newfoundland. J. H. L. and M. E. P. thank NSERC for Undergraduate Student Research Awards.

\section{References}

1 R. T. Martin, L. P. Camargo and S. A. Miller, Green Chem., 2014, 16, 1768-1773.

2 J. M. Becker and A. P. Dove, in Green Polymerization Methods: Renewable Starting Materials, Catalysis and Waste Reduction, eds. R. T. Mathers and M. A. R. Meier, WileyVCH, Weinheim, 1st edn, 2011, pp. 201-220.

3 R. E. Drumright, P. R. Gruber and D. E. Henton, $A d v$. Mater., 2000, 12, 1841-1846.

4 O. Dechy-Cabaret, B. Martin-Vaca and D. Bourissou, Chem. Rev., 2004, 104, 6147-6176.

5 M. J. Stanford and A. P. Dove, Chem. Soc. Rev., 2010, 39, 486-494.

6 C. A. Wheaton, P. G. Hayes and B. J. Ireland, Dalton Trans., 2009, 4832-4846.

7 M. H. Chisholm and Z. P. Zhou, J. Mater. Chem., 2004, 14, 3081-3092.

8 B. J. O'Keefe, M. A. Hillmyer and W. B. Tolman, J. Chem. Soc., Dalton Trans., 2001, 2215-2224.

9 O. Wichmann, R. Sillanpää and A. Lehtonen, Coord. Chem. Rev., 2012, 256, 371-392.

10 N. Ikpo, C. Hoffmann, L. N. Dawe and F. M. Kerton, Dalton Trans., 2012, 41, 6651-6660.

11 Y. Huang, Y.-H. Tsai, W.-C. Hung, C.-S. Lin, W. Wang, J.-H. Huang, S. Dutta and C.-C. Lin, Inorg. Chem., 2010, 49, 9416-9425. 
12 L. Wang, X. B. Pan, L. H. Yao, N. Tang and J. C. Wu, Eur. J. Inorg. Chem., 2011, 632-636.

13 C.-A. Huang, C.-L. Ho and C.-T. Chen, Dalton Trans., 2008, 3502-3510.

14 C. A. Huang and C. T. Chen, Dalton Trans., 2007, 55615566.

15 F. M. Kerton, C. M. Kozak, K. Lüttgen, C. E. Willans, R. J. Webster and A. C. Whitwood, Inorg. Chim. Acta, 2006, 359, 2819-2825.

16 B.-T. Ko and C.-C. Lin, J. Am. Chem. Soc., 2001, 123, 79737977.

17 W. Clegg, M. G. Davidson, D. V. Graham, G. Griffen, M. D. Jones, A. R. Kennedy, C. T. O'Hara, L. Russo and C. M. Thomson, Dalton Trans., 2008, 1295-1301.

18 Z. Janas, T. Nerkowski, E. Kober, L. B. Jerzykiewicz and T. Lis, Dalton Trans., 2012, 41, 442-447.

19 L. E. Breyfogle, C. K. Williams, V. G. Young, M. A. Hillmyer and W. B. Tolman, Dalton Trans., 2006, 928-936.

20 J. Ejfler, S. Szafert, K. Mierzwicki, L. B. Jerzykiewicz and P. Sobota, Dalton Trans., 2008, 6556-6562.

21 W. C. Hung and C. C. Lin, Inorg. Chem., 2009, 48, 728-734.

22 E. L. Marshall, V. C. Gibson and H. S. Rzepa, J. Am. Chem. Soc., 2005, 127, 6048-6051.

23 Y. Sarazin, V. Poirier, T. Roisnel and J.-F. Carpentier, Eur. J. Inorg. Chem., 2010, 3423-3428.

24 A. D. Schofield, M. L. Barros, M. G. Cushion, A. D. Schwarz and P. Mountford, Dalton Trans., 2009, 85-96.

25 X. Zhang, T. J. Emge and K. C. Hultzsch, Organometallics, 2010, 29, 5871-5877.

26 D. J. Darensbourg, W. Choi, O. Karroonnirun and N. Bhuvanesh, Macromolecules, 2008, 41, 3493-3502.

27 H. E. Dyer, S. Huijser, A. D. Schwarz, C. Wang, R. Duchateau and P. Mountford, Dalton Trans., 2008, 3235.

28 A. Amgoune, C. M. Thomas and J.-F. Carpentier, Macromol. Rapid Commun., 2007, 28, 693-697.

29 M. H. Chisholm, J. C. Gallucci, H. H. Zhen and J. C. Huffman, Inorg. Chem., 2001, 40, 5051-5054.

30 C. K. Williams, N. R. Brooks, M. A. Hillmyer and W. B. Tolman, Chem. Commun., 2002, 2132-2133.

31 C. K. Williams, L. E. Breyfogle, S. K. Choi, W. Nam, V. G. Young, M. A. Hillmyer and W. B. Tolman, J. Am. Chem. Soc., 2003, 125, 11350-11359.

32 D. J. Doyle, V. C. Gibson and A. J. P. White, Dalton Trans., 2007, 358-363.

33 J. D. Farwell, P. B. Hitchcock, M. F. Lappert, G. A. Luinstra, A. V. Protchenko and X.-H. Wei, J. Organomet. Chem., 2008, 693, 1861-1869.

34 G. Labourdette, D. J. Lee, B. O. Patrick, M. B. Ezhova and P. Mehrkhodavandi, Organometallics, 2009, 28, 1309-1319.

35 L. Wang and H. Ma, Dalton Trans., 2010, 39, 7897-7910.

36 N. Ikpo, L. N. Saunders, J. L. Walsh, J. M. B. Smith, L. N. Dawe and F. M. Kerton, Eur. J. Inorg. Chem., 2011, 5347-5359.

37 V. Poirier, T. Roisnel, J.-F. Carpentier and Y. Sarazin, Dalton Trans., 2011, 40, 523-534.
38 J. Lewinski, P. Horeglad, M. Dranka and I. Justyniak, Inorg. Chem., 2004, 43, 5789-5791.

39 J.-T. Issenhuth, J. Pluvinage, R. Welter, S. Bellemin-Laponnaz and S. Dagorne, Eur. J. Inorg. Chem., 2009, 4701-4709.

40 S. Gendler, S. Segal, I. Goldberg, Z. Goldschmidt and M. Kol, Inorg. Chem., 2006, 45, 4783-4790.

41 S. Groysman, E. Sergeeva, I. Goldberg and M. Kol, Inorg. Chem., 2005, 44, 8188-8190.

42 L. M. Broomfield, Y. Sarazin, J. A. Wright, D. L. Hughes, W. Clegg, R. W. Harrington and M. Bochmann, J. Organomet. Chem., 2007, 692, 4603-4611.

43 L. N. Saunders, L. N. Dawe and C. M. Kozak, J. Organomet. Chem., 2014, 749, 34-40.

44 R. K. Dean, A. M. Reckling, H. Chen, L. N. Dawe, C. M. Schneider and C. M. Kozak, Dalton Trans., 2013, 3504-3530.

45 R. H. Platel, L. M. Hodgson and C. K. Williams, Polym. Rev., 2008, 48, 11-63.

46 J. H. Khan, F. Schue and G. A. George, Polym. Int., 2009, 58, 296-301.

47 M. R. Kember and C. K. Williams, J. Am. Chem. Soc., 2012, 134, 15676-15679.

48 L. Wang and H. Ma, Macromolecules, 2010, 43, 6535-6537.

49 S. Song, H. Ma and Y. Yang, Dalton Trans., 2013, 42, 1420014211.

50 E. Kober, Z. Janas, T. Nerkowski and L. B. Jerzykiewicz, Dalton Trans., 2013, 42, 10847-10854.

51 M. G. Davidson, M. D. Jones, D. Meng and C. T. O’Hara, Main Group Chem., 2006, 5, 3-12.

52 J. Ejfler, K. Krauzy-Dziedzic, S. Szafert, L. B. Jerzykiewicz and P. Sobota, Eur. J. Inorg. Chem., 2010, 3602-3609.

53 Y. Sarazin, R. H. Howard, D. L. Hughes, S. M. Humphrey and M. Bochmann, Dalton Trans., 2006, 340-350.

54 F. M. Kerton, S. Holloway, A. Power, R. G. Soper, K. Sheridan, J. M. Lynam, A. C. Whitwood and C. E. Willans, Can. J. Chem., 2008, 86, 435-443.

55 S. Menage, G. Gellon, J.-L. Pierre, D. Zurita and E. SaintAman, Bull. Soc. Chim. Fr., 1997, 134, 785-791.

56 S. Heidari, E. Safaei, A. Wojtczak, P. Cotic and A. Kozakiewicz, Polyhedron, 2013, 55, 109-116.

57 T. R. Forder, M. F. Mahon, M. G. Davidson, T. Woodman and M. D. Jones, Dalton Trans., 2014, 43, 12095-12099.

58 A. W. Addison, T. N. Rao, J. Reedijk, J. van Rijn and G. C. Verschoor, J. Chem. Soc., Dalton Trans., 1984, 1349.

59 A. C. Silvino, D. Bonilha de Abreu Talina Martins, A. da Costa Rodrigues and M. L. Dias, J. Polym. Environ., 2013, 21, 1002-1008.

60 A. D. Schwarz, Z. Chu and P. Mountford, Organometallics, 2010, 29, 1246-1260.

61 G. Xiao, B. Yan, R. Ma, W. J. Jin, X. Q. Lu, L. Q. Ding, C. Zeng, L. L. Chen and F. Bao, Polym. Chem., 2011, 2, 659664.

62 C. Paetz and R. Hagen, Chem. Ing. Tech., 2014, 86, 519-523.

63 M. Bouyahyi, E. Grunova, N. Marquet, E. Kirillov, C. M. Thomas, T. Roisnel and J.-F. Carpentier, Organometallics, 2008, 27, 5815-5825. 
64 A. J. Chmura, M. G. Davidson, C. J. Frankis, M. D. Jones and M. D. Lunn, Chem. Commun., 2008, 1293-1295.

65 J. Baran, A. Duda, A. Kowalski, R. Szymanski and S. Penczek, Macromol. Rapid Commun., 1997, 18, 325-333.

66 K. Jamshidi, S. H. Hyon and Y. Ikada, Polymer, 1988, 29, 2229-2234.

67 S.-H. Lee, S. Hyun Kim, Y.-K. Han and Y. H. Kim, J. Polym. Sci., Part A: Polym. Chem., 2001, 39, 973-985.
68 Z. Zhong, P. J. Dijkstra and J. Feijen, Angew. Chem., Int. Ed., 2002, 41, 4510-4513.

69 Y. Sarazin, S.-C. Rosca, D.-A. Rosca, V. Dorcet, J.-F. Carpentier, F. M. Kerton and C. M. Kozak, Dalton Trans., 2013, 9361-9375.

70 N. Ajellal, J.-F. Carpentier, C. Guillaume, S. M. Guillaume, M. Helou, V. Poirier, Y. Sarazin and A. Trifonov, Dalton Trans., 2010, 39, 8363-8376. 